\title{
HOW SAFE IS SAFE? A CANADIAN AIR CARRIERS (CAC) SAFETY BEHAVIOR INVESTIGATION
}

\author{
Angeline Ram \\ University of Waterloo, Waterloo, Canada \\ Centre for Air Transport, Cranfield University, Bedford MK43 OAL, UK \\ John F. O'Connell \\ Centre of Aviation Research, School of Hospitality and Tourism Management, University of \\ Surrey, Guildford, GU2 7XH, UK \\ Marina Efthymiou (corresponding author) \\ DCU Business School, Dublin City University, Dublin 9, Ireland \\ Eric Tchouamou Njoya \\ Huddersfield Business School, Department of Logistics, Marketing, Hospitality, and Analytics, \\ The University of Huddersfield, HD1 3DH, Huddersfield, UK
}

\begin{abstract}
The importance of safety within an organization is determined by the implementation of a Safety Management System (SMS), organizational culture, management commitment and behaviour, the activity of staff themselves, and to what degree safety reporting is upheld (Cohen, Wiegmann and Shappell, 2015). Canada was the first country globally to implement regulation mandating a Safety Management System (SMS) program. Many Canadian air carriers (CAC) proudly announce safety as a top priority, which is achieved through their SMS program. Amidst aviation's verbal safety saturation, safety is often communicated as the top priority within the industry; however, are the public declarations consistent with CAC practices? This paper investigates whether safety behaviour within CAC is aligned to the objectives of the SMS. In-depth interviews with seven senior safety experts were conducted to identify areas of improvement and a survey with 164 respondents. This research found that there are many areas of improvement of the safety performance of CAC. Factors, which affect safety reporting behaviour and the priority of safety, include management's support of a safety culture, job function, and the number of air carriers an individual has worked for. This research also suggests that a job function that was created to instil public confidence is more likely to deviate from safety procedures and less likely to report. A template for safety success, which influences organizational culture resulting in economic viability output, is proposed and recommendations for safety culture enforcement by the regulators.
\end{abstract}

\section{KEYWORDS}

aviation safety, Safety Management System, organizational culture, Canadian Air Carriers, safety management. 


\section{INTRODUCTION}

Population growth, global aging and middle class growth has contributed to the development of air transport (Efthymiou et al., 2016). Aviation is a highly regulated industry where the word safety is scribed on walls and documented through regulation and standard operating procedures. Nevertheless, safety incidents are quite common and with the constant growth of aviation safety incidents will only increase unless transport authorities do not prioritize safety. In 2012, the Office of Auditor General of Canada communicated that Canadian aviation's principal obligation was to sustain safe air travel (Office of Auditor General of Canada, 2012). With this declaration, however, its implementation as a stated priority is not consistent with observed practices within organizations.

Several scholars have researched safety. Murphy and Efthymiou (2017) researched the aviation safety regulation in the multi-stakeholder environment. Janic (2000) looked at risk and safety in civil aviation and the main causes of aircraft accidents. Kelly and Efthymiou (2019) analysed the human factors in fifty aviation accidents and identified 1289 individual causal and contributory human factors with unsafe actions and preconditions for unsafe actions being the main subcategories of the accidents. O'Connor et al. (2011) and Gill and Shergill (2004) researched safety climate/culture in aviation. Pidgeon and O'Leary analysed organizational safety culture and identified the implication for aviation. Wiegmann et al. (2009) discussed the key organizational indicators of safety culture and the various assessment methods.

Cohen et al. (2015) suggest that the importance of safety within an organization is determined by the implementation of a SMS, organizational culture, management commitment and patterns of behaviour, the activity of staff themselves, and to what degree safety reporting is upheld. This paper investigates the underpinning factors that influence the priority of safety using Canada as a case study.

This article is organized as follows. In section two, an exhaustive literature review discusses the global aviation's safety perspective. The literature review provides a roadmap of factors that contribute to safety. These factors include management commitment/behaviour, organizational culture, SMS, financial benefits of safety, and employee perception and safety behaviours. Research has identified that multiple factors influence front line staff's perception and behaviour towards safety reporting as well as the relationship between safety and cost. 
In section three, the research methods and analysis for the mixed-method approach of both quantitative and qualitative data are identified. In section four, the perspective of experts through exploratory analysis establishes five reoccurring themes, which are interlinked: management commitment, organizational culture, and effective implementation of a safety system. In section five, data analysis shows that both respondents and experts identify that safety is not the number one priority as a stated commitment, yet most respondents believe that safety should be considered when making a business decision. In the final section, the article is concluded by reiterating the importance of management commitment and the necessity of regulator enforcement of Accountable Executive participation in the safety system. Six recommendations to the regulator, a template to promote organizational safety culture and SMS by middle management and front-line staff titled Management in Middle (M in $\mathrm{M}$ ) is proposed as well as further research topics.

\section{STATE OF THE ART REVIEW OF SAFETY AREA}

In the mid-1990s, at the commencement of the organizational era, the notion of organizational accidents was born (Reason, 1997). By understanding how accidents occurred within an organization, conditions, which allow for an undesirable outcome could be mitigated (ICAO, 2013).

James Reason's accident causation model, known as the "Swiss Cheese" model, is widely accepted by ICAO, academics, and aviation in explaining how accidents occur. Reason's theory draws on the relationship of the various layers that constitute an organization, while researchers like Edgar Schein (1985) explain why organizations behave as they do.

\subsection{Safety Culture}

The concept of organizational culture is multi-layered and complex. ICAO (2013) states, culture is characterized by the beliefs, values, biases, and resultant behaviour that are shared by members of a society, group, or organization (ICAO, 2013). Edgar Schein (1985, p6), defines culture as:

A pattern of basic assumptions, invented, discovered or developed by a given group; that has worked well enough to be considered valid and, therefore, to be taught to new members as the correct way to perceive, think, and feel concerning those problems. 
Schein further adds that culture is comprised of subcultures specific to departments or groups of people who comprise an organization. In the context of aviation, this suggests that the subculture for job functions all differ.

Zhang (2002, p1406) suggests that safety culture is observed through behaviour from members of an organization. Research from a sample of 1,751 respondents including: captains, first officers, pursers and flight attendants surveyed showed that crew of a lesser status (all participants other than the captain) preferred to remain silent in order to maintain a "positive team dynamic" than speak up (Bienefeld and Grote, 2012, p10). This silence is in direct conflict to Crew Resource Management training which is taught to all operational aviation staff and reiterated annually in the interest of safety promotion and silo deconstruction (Bienefeld and Grote, 2012).

Wiegmann et al. (2017) have determined that an organization's upper-level management has long been recognized as playing a critical role in promoting organizational safety culture. While Antonsen et al. (2016, p232) add that an organization's behaviour and communication greatly influence the outcome of safety-critical decisions. Employees not only mirror the behaviours of management, but also those of co-workers, to understand what behaviours are acceptable (Pinion et al. 2017). When the underlying beliefs within an organization (culture) establish behavioural norms, most employees aspire to fit into an organization's culture (Schein, 1985).

Despite variations in safety culture research, the recurring factors identified within organizational safety culture by aviation research academics such as Wiegmann et al. (2017) and Zhang et al. (2002) include management commitment, employee behaviour, and safety reporting; which all contribute to the priority of safety in air transportation.

\subsubsection{Management Commitment}

Wiegmann et al. (2017) suggest that upper management is an essential component in creating an organization's safety culture. Commitment to safety is reciprocal between management and employees. Yuan et al. (2015, p165) affirm that when employees feel that there is a concern for their safety and well-being, they are motivated to fulfil safety and job requirements. Varmazyar et al.'s (2014) research establishes that commitment to safety in organizations directly correlates to resources provided by upper management, inclusive of training and equipment in addition to the safety measures implemented (Von Thaden and Gibbons, 2008). 
Bosak et al. (2013) add that management's attitude toward safety impacts acceptable levels of risk. Lu and Chen (2015) contend that when management leads by regulatory requirements and strategy, such as the documented processes of the regulatory framework of SMS, the focus is on efficiency and not the safety interests of individuals. Gillen et al. (2004, p248) emphasizes the impact of management's actions, stating that the way safety policies are implemented is also important to workers, so that they can respect, rather than resent, the enforcement.

\subsubsection{Communication}

The messages most often communicated have a positive or negative impact on the workforce and encourage motivation, participation or lack thereof (Huang et al., 2017). The information disseminated throughout the organization further reinforces the perception of employees' safety beliefs. Bosak et al. (2013) indicate that consistent safety communication demonstrates management's commitment to safety. Somoo $(2012$, p12) suggests that demonstrated written and verbal commitment and involvement in the organization's safety indicates management's commitment to assuming ownership of the organization's safety program.

Wiegmann et al. (2017) corroborate that communication, verbal and in writing, is only one aspect of an organization's commitment to safety. Management's commitment to tangible safety is equally as impactful as the subconscious effects of their communications and interactions with stakeholders.

Lin (2012), whose research focused on the impact of policies on the pilot group, proposes that efforts to enhance safety will not be readily accepted if employees are unable to identify what messages or policies are communicated. Additionally, Lin (2012) adds that if management's messages are incongruent with employee actions, feelings of animosity may arise.

Zohar and Polachek (2014) suggest that changes in messages from management result in altered priorities, which trickle into behaviours that are only measured during safety audits. If managers state that the personal safety of their employees is of the utmost importance, yet fail to act on safety concerns, the manager is implicitly communicating that the priorities of employees are not as important as previously communicated. Von Thaden et al. (2008, p5) assert that obscurity in management's messages may encourage employees to place less value on safety while making it acceptable to cut corners where safety is concerned. Pinion et al. (2017) conclude that when managers and top-level leadership explicitly and implicitly express safety values through verbiage and behavioural modelling, employees will follow suit. 


\subsection{Concept of Safety}

The word safety has been synonymous with aviation since the inception of the International Civil Aviation Organization (ICAO) in 1944. ICAO (2013, p2-1) defines safety as the state in which the possibility of harm to a person or of property damage is reduced to, and maintained at or below, an acceptable level through a continuous process of hazard identification and risk management. In contrast with the Cambridge Dictionary, ICAO establishes that safety is a state with an acceptable level of risk; the standard dictionary definition refers to a state of being or with free or danger or risk free (Cambridge, 2017; ICAO 2013; Siegenthaler, 2015).

ICAO (2013, p2-1) suggests that as long as safety risks are managed to organizations acceptable levels, a dynamic safety can effectively balance production and protection (Siegenthaler, 2015). Further dimensions of safety include culture, reporting, performance indicators, risk, risk management, and oversight (ICAO (2013).

Risk management is an essential component of safety management. According to ICAO (2013, p5-1) SMS is meant to assure the safe operation of aircraft through effective management of safety risk. The SMS is designed to continuously improve safety by identifying hazards, collecting and analyzing data, and continuously assessing safety risks. To ensure that states are meeting SMS requirements, ICAO requires system oversight by regulators.

\subsection{Safety as a Business Function}

Aviation's SMS expectation is that risk management is incorporated into business decisions and managed similarly to a business management activity. The process includes a review, performance oversight, and financial monitoring (ICAO, 2013). Lercel et al. (2011) affirm that the safety program's financial oversight allows for tracking costs associated with safety events and cost-saving through safe practices.

Håvold, who studied safety programs in the petroleum sector, agrees with Lercel. Håvold (2010, p513) states that an organization with a 'safety culture' is one that gives appropriate priority to safety and realizes that safety must be managed in the same way as other areas of the business by being included in the business plan.

Gnoni and Saleh (2017) suggest that historically importance was not placed on safety improvement throughout an organization. However, Gnoni and Salehl (2017), and Marcario et al. (2015) agree that the prioritization of safety assists in the prevention of accidents. Von 
Thaden and Gibbons (2008) argue that a SMS should be viewed as a necessary business investment.

\subsection{Financial Benefits of Safety}

Profitability is paramount to the survivability of aviation as an industry (Efthymiou et al., 2019; Efthymiou and Papatheodorou, 2018; O'Connell et al., 2020) and accident prevention supports profitability. In 2014, the world witnessed the financial effects suffered by Malaysian Airlines (Hodgson et al., 2015). The New York Times (2014) published that the airline, which was under financial difficulty before the accidents, suffered an increased quarterly loss of USD 97.6 million compared to $\$ 55.9$ million in the previous quarter. Hodgson et al. $(2015, \mathrm{p} 35)$ suggest that the impact on Malaysian Airline's reputation with passengers was one from which they failed to recover, with a decrease in sales, an increase in flight cancellations, and refunds requested from passengers despite reduced fares and free ancillary offerings. Hodgson et al. (2015, p34) add that Malaysian Airlines lost 40\% of its customer base because of the first accident and following the second accident (within four months),80\% of the customer base had chosen other air carriers.

Lercel et al.'s (2011, p9) study of a Maintenance Repair Organization (MRO) demonstrates inadequate safety management of one event associated with the incorrect installation of a door connector following painting. One event costs USD 27,000. Due to inadequate action, the same event occurred four times that year, with a total of $\$ 108,000$ to rectify the damage. Lercel et al. (2011) estimate that the MRO would have seen a $983 \%$ return on investment if a system had proper SMS action been taken resulting in a suitable corrective action. With thin profit margins in aviation, a financial loss of any kind further impedes revenue streams. Identifying safety gaps or repetitive damage drives profitability in the long-term.

As of March 2019, global aviation has witnessed the grounding of all B737-Max aircraft following the 2018 Lion Air Crash followed by the 2019 Ethiopian Airlines Crash. In August 2019, the Federal Aviation Association (FAA) of the United States of America issued a statement stating the FAA (2019) commitment to return safe aircraft into service.

In January 2020, the FAA communicated the importance of extending SMS into various aspects of American Aviation, including the certification process (FAA, 2020). The absence of adequate safety controls has cost Boeing an estimated loss of $\$ 40$ million in the last quarter of 2019 (Flight Global 2019). 


\subsection{Safety Culture and Safety Management}

Somoo (2012, p12) links organizational culture to SMS arguing that effective safety management requires senior leadership responsibility in establishing a safety culture. Somoo's safety culture versus causation model shows the interrelationships between the implementation of an SMS program and safety culture. This model establishes that positive organizational safety culture impacts management's commitment and safety promotion, which results in the successful implementation of a safety management system. This relationship between SMS and safety culture is further explained by Gordon et al. (2007, p. 674) who describe safety culture being less tangible than the system yet working hand in hand to achieve safety within an organisation.

\subsection{Defining Safety in Canada}

The Canadian Aviation Regulations (CARs) do not define the word safety but do define its management through the Safety Management System. Both ICAO and Transport Canada Civil Aviation (TCCA) strive for an elimination of aircraft accidents and serious incidents (ICAO, 2013; Transport Canada, 2008), with one major divergence as detailed in TCCA Advisory Circular No 107-001. TCCA recommends (2008) that CAC communicates the expectations of zero incidents.

Without a definition of aviation safety, or reference to ICAO's definition of safety, employees of CAC may not know ICAO's definition of safety and may subscribe to a ubiquitous understanding of safety. Adding to the misperception, (ICAO, 2013), a goal of "zero incidents", if taken literally, would indicate that CAC believes a goal of "zero incidents" is a realistic benchmark (Transport Canada, 2008). TCCA (2008) expects CAC to strive for "zero safety incidents" achieved through an SMS. However, by the very definition of aviation safety, safety refers to a reduction in risk rather than an elimination.

Without defining safety in Canadian aviation, subjective judgment calls from air carriers and regulatory inspectors may lead to variation in the implementation of safety regulations or focus, as observed by the author, who has worked in Canadian Aviation in various Safety Management roles. Such subjectivity means that safety errors and gaps are not uniformly and consistently managed. Subjectivity prevents a ubiquitous understanding and application of an organizational understanding of safety. 
In Canada, eight airlines, have undertaken IATA's safety validation process (Transport Canada, 2017). All airlines that have IATA ratings are the largest carriers or subsidiaries of the largest carriers in the country and have benefited from international business, such as codeshares through this validation process. Of the Twenty-six non-IATA air carriers in Canada, most $(19$, or $70 \%)$ referred to safety on their website, and less than half $(12$, or $44 \%)$ referred to the use of a SMS ${ }^{1}$.

It appears that most CAC has acquired and international safety best practice qualification and are assumed to operate at the minimum acceptable level of safety as outlined in the Canadian Aviation Regulations (CARs). However, the majority of CAC communicate the importance of safety and almost half promote the use of a safety system program to the travelling public.

\section{RESEARCH METHODS}

\subsection{Methods to reach Research Objectives}

The methodology in this paper is based on a mixed-method approach, which allows the consolidation of quantitative data from surveys, qualitative data from semi-structured expert interviews and responses from semi-structured survey questions. The mixed-method approach was chosen as a means to compare the opinions of those managing safety in Canada to those who are responsible for the implementation of safety practices. The survey and interview data were gathered under the condition of anonymity and approval of the ethics committee. Interviewees were given a number and descriptor.

Table 1 summarizes the method and approach used to accomplish the paper's aim. Given the regulatory framework and subjective execution of "safety" throughout CACs, three objectives have been identified.

Table 1. Research objectives and methodological approach

\begin{tabular}{|l|l|}
\hline Objectives & Approach \\
\hline $\begin{array}{l}\text { Objective 1: Conduct a } \\
\text { comprehensive literature review }\end{array}$ & $\begin{array}{l}\text { This objective was met by conducting a } \\
\text { comprehensive literature review including }\end{array}$ \\
identifying the underpinning factors & $\begin{array}{l}\text { publications from ICAO, TCCA, academic journals, } \\
\text { which impact the priority of safety } \\
\text { trade books, and safety theses, in addition to } \\
\text { globally and how it is translated to } \\
\text { CAC. }\end{array}$ \\
\hline
\end{tabular}

${ }^{1} \mathrm{~A}$ concept not understood by the public and often misunderstood by aviation professionals. 


\begin{tabular}{|l|l|}
\hline & $\begin{array}{l}\text { Wiegmann and Shappell's HFACS methodology } \\
\text { workshop (2017). }\end{array}$ \\
\hline $\begin{array}{l}\text { Objective 2: Conduct a case study } \\
\text { with expert feedback regarding a } \\
\text { robust SMS program, the priority of } \\
\text { safety, and the support of sufficient } \\
\text { resources and engaged management } \\
\text { in upholding safety within CAC. }\end{array}$ & $\begin{array}{l}\text { objective was accomplished by conducting semi- } \\
\text { structured expert interviews with seven experts } \\
\text { from the Canadian aviation industry, including } \\
\text { experts from the TCCA and ICAOs Safety } \\
\text { Management International Collaboration group. All } \\
\text { interviews were analyzed for commonalities to } \\
\text { identify trends. }\end{array}$ \\
\hline $\begin{array}{l}\text { Objective 3: Comprehend the } \\
\text { perception of safety management } \\
\text { culture from the perspective of CAC } \\
\text { employees, and identify the impact of } \\
\text { organizational culture and how the } \\
\text { views of the experts align with the } \\
\text { practical world. }\end{array}$ & $\begin{array}{l}\text { This is the final objective of the article. Due to the } \\
\text { limited and proprietary nature of the information of } \\
\text { data in Canada aviation, primary exploration from } \\
\text { the perspective of respondents from CAC was an } \\
\text { essential component in collecting primary data } \\
\text { unique to this topic. This objective was undertaken } \\
\text { through an extensive, comprehensive semi- } \\
\text { structured online survey of 164 responses from } \\
\text { associates from Canadian air carriers. Following the } \\
\text { structured questions, a short answer option was } \\
\text { available for respondents. The data were analyzed } \\
\text { in conjunction with expert opinions. Trends, } \\
\text { commonalities, and differences were identified and } \\
\text { reported. }\end{array}$ \\
\hline
\end{tabular}

\subsection{Quantitative and Qualitative Approach}

The survey was created online in Google Forms. The data collection was open from January 6,2017 , to February 21, 2017. The survey had a total of 16 questions; there was a combination of question styles; incorporating a five-point Likert scale ranging from "strongly disagree" to "strongly agree"; together with multiple choice, and ranking questions.

The survey was designed to incorporate key elements of previous research including organizational safety communication, task focus, and management as role models, reporting, and organizational culture. The survey questions included the following topics: demographics (4 questions), company safety perspective (Q1), management as an example (Q2), risk in aviation (Q3), role of TCCA \& safety departments (Q4), deviation from procedures (Q5), work focus (Q6), communication (Q7), reporting (Q8-9), factors contributing to safety (Q10), and organizational focus and priority (Q11-12).

The survey link was disseminated to individuals who are known employees of CAC through the researcher's list of personal contacts on LinkedIn and Facebook. In addition, postings were 
made on Facebook Canadian aviation chat groups2, inviting members' participation in the survey. Some primary recipients shared the link on their Facebook pages.

The qualitative approach consists of semi-structured interviews conducted with seven aviation experts. Interviews were administered in person, by phone, by email, or some combination thereof and recorded, then annotated. The sample for the qualitative research included Canadian aviation safety experts whose aviation experience ranged from 20-45 years, both in Canada and internationally, within various safety roles. The average in-person interview was 90 minutes long, involving discussion on approximately 24 questions. The semi-structured interviews provided a uniform format while still enabling experts the freedom to elaborate on specific topics. The interview questions were grouped into six categories: safety challenges, successful implementation of SMS, measuring safety culture, Reason's "Swiss Cheese" model and other models, which support an SMS, and the importance and priority of safety from their perspective.

Table 2. List of Safety experts interviewed

\begin{tabular}{|l|l|}
\hline $\begin{array}{l}\text { Expert } \\
\text { Identifier }\end{array}$ & Area of Expertise \\
\hline Expert 1 & Director of Flight Operations, CAR 604/704 Operator - Business Aviation \\
\hline Expert 2 & Director of Safety, CAR 705 Operator - Commercial Aviation \\
\hline Expert 3 & SMS Manager, CAR 705 Operator - Commercial Aviation \\
\hline Expert 4 & Transport Canada - Regulator \\
\hline Expert 5 & $\begin{array}{l}\text { ICAO Safety Management International Collaboration Group Member - } \\
\text { Regulator }\end{array}$ \\
\hline Expert 6 & Director of Approved Training Organization \\
\hline Expert 7 & Manager Cabin Crew, CAR 705 Operator - Commercial Aviation \\
\hline
\end{tabular}

Qualitative data was also gathered from nine open response questions incorporated into the online survey. Examples of open-ended questions include: "we would like to know more about your thoughts regarding safety," and "if you disagree with this statement, please tell us why." All interviews were transcribed for data analysis.

The data were analyzed through descriptive statistics and both univariate and bivariate analysis. Categorical data were summarized using frequency and percentages. A chi-square test was used to explore relationships. A chi-square inferential test and cross-tabulation tables were used to quantify relationships between two categorical variables. All inferential analysis

\footnotetext{
${ }^{2}$ An example of a Facebook Aviation group is Canadian Women in Aviation.
} 
was performed with 0.05 level of statistical significance. Content analysis was used to identify common themes from both the expert interviews and the open-ended survey questions.

\section{CASE STUDY FINDINGS}

To gain a better understanding of SMS and the priority of safety in Canadian aviation, seven aviation experts were interviewed. These experts have been instrumental in the development and/or implementation of SMS within Canada. The experts were asked to list the top three challenges faced in achieving safety in Canada. The top three areas of development identified include: management commitment, organizational culture, and implementation of an SMS.

Expert 6, having implemented multiple SMS programs within Canada, declares a lack of management commitment results from the belief that "a lot of airlines think that they are safe; it's like telling someone to eat well and exercise when they already feel good." Expert 6 adds "it is a stark reality that an accident or an incident will cost them so much more than a SMS...if they have an accident, it will wipe their company out."

Expert 2elucidates on the second top-ranking area of development and organizational culture, affirming its link to management. "Culture needs to be fostered from an organization and leadership; however, safety cultures vary with the leadership." Expert 2 describes the implementation of SMS as "not fully implemented as ICAO intended. We are gaining a better understanding of quality management into safety, and are moving from reactive to proactive to predictive, but slower than expected."

\subsection{Safety Challenges - Implementation of National SMS}

The challenges faced by the implementation of a national SMS framework are transverse to areas of safety development. These challenges include management commitment and implementation of their SMS program. Experts 4,5, and 6 agreed that continuous SMS momentum through organizational support (management commitment) is incumbent on successful implementation. Expert 6, who trained TCCA Inspectors and consulted with numerous air carriers at the onset of SMS regulation, asserts the importance of continuous improvement with SMS implementation. "I've come back after a year and found that organizations... have fallen back to the way they have done things in the past." Experts 4, 5, and 6 agree that SMS needs to be more than just regulatory compliance. Expert 5, a key 
player in SMS development, expresses "it's not about compliance; it's about developing criteria that work for an airline. Expert 6 further adds "that is the whole point with SMS, they are supposed to meet the regulation and so much more. Expert 7 agrees with both challenges listed in Table 3, "consistent management commitment to the objective," is our limitation to SMS implementation.

Table 3. Challenges with SMS implementation as identified by the Experts

Challenges of SMS Implementation

Management Commitment (continuous SMS momentum)

Implementation of a system rather than regulatory compliance
Experts Who Responded

Expert 1, 3,4, 5, 6

Expert 4, 5, 6

In the absence of a one size fits all approach to successful SMS implementation, Experts 4,5, and 6 affirm that safety should be tailored to rectify the gaps and needs of each organization. The top three factors for successful implementation of SMS include management commitment, organizational involvement, and quality principles for SMS (table 4).

Table 4. Factors that contribute to successful SMS implementation as identified by the Experts

\begin{tabular}{|l|l|}
\hline $\begin{array}{l}\text { Factors that contribute to successful SMS } \\
\text { Implementation }\end{array}$ & Experts Who Responded \\
\hline Organizational involvement & Expert 1,2,3,4,5,6,7 \\
\hline Management Commitment & Expert 1, 2, 4, 5,6,7 \\
\hline Quality principles of SMS & Expert 2,3,4,5,6,7 \\
\hline Risk control/mitigation & Expert 4,5,6 \\
\hline Reporting and feedback to employees & Expert 3 \\
\hline Incremental changes in the right direction & Expert 1 \\
\hline
\end{tabular}

\subsection{Safety and SMS Success}

Experts' 1, 2, 4, 5, 6 and 7 opinions reveal that the challenges/areas of development for safety and SMS are identical to the factors that have contributed to the successful implementation of SMS: management commitment and organizational culture.

Expert 5 shared that successful implementation of a SMS can be achieved through a safetyconscious organizational culture, which is shaped by management. "A safety management system is just infrastructure unless you have a culture...which lays the foundation," and gives safety a high level of importance. 


\subsection{Success of National SMS in Global Comparisons}

In benchmarking Canada's success with SMS implementation, experts were asked how they view the success of SMS to that of other countries. Experts 1, 3, 4, 5 and 6 agreed that Canadian aviation organizations have been progressive with the implementation of SMS. "We have moved regulation forward [in various capacities of aviation], although EASA may have done a better job" (Expert 5). Expert 3 states, "I believe it has been a great success because Canada was the first country to make it mandatory." Expert 4, having worked with SMS on an international level states, "ours is broader than [ICAO] Annex 19; we include an internal audit program. It's not a limitation, it's an enhancement."

Expert 1 compared Canada's SMS to that of the USA and concluded that Canada was progressive when compared to "third world countries," ${ }^{3}$ yet it fell short of effective implementation in comparison to the EU.

\subsection{Measuring Safety Culture}

The experts identified three commonalities in measuring CAC safety culture. These include adequate resources, management commitment, and regulatory compliance as shown in Table 5. Experts 4 and 5 attest that there is a relationship between resources, management commitment, and regulatory compliance. Adequate resources include the appropriate number of staff, staff training, resources for safety enhancements, and demonstration of a "just culture" environment. This environment supports a culture in which employees are comfortable raising concerns, are encouraged by management to be safety-minded, and where a safety program is fostered and promoted across the organization.

Experts 2, 4, 5, 6 and 7 agreed that adequate resources allocated to a safety department demonstrate investment in and value given to safety. When the "Accountable Executives supports safety, safety is given importance and value in an organization," Expert 7 states. Expert 2 adds that a company's commitment to an investment in a SMS program is "based on the Accountable Executive".

Experts 4 and 5 agree that the "compliance and effectiveness of a system is an indicator of culture. Expert 3 was the only one who identified reporting as an independent variable, and

\footnotetext{
${ }^{3}$ Although Canada's SMS was progressive when compared to that of "third world countries," it is noteworthy to add that that in 2011, countries listed on the Third World Human Development Index include Kenya, Ethiopia and Pakistan; all whose national airlines are IOSA qualified and code share internationally (Nations online, 2017).
} 
as a measure of safety culture. However, Expert 2 maintains that the correlation of multiple factors contributes to safety culture. Expert 2 asserts: "Reporting is an indicator of a safety culture, but a reporting culture is not the only measure of a safety culture. Balance of operations and safety, and costs for safety investments, how we support our employees when they make mistakes, those are all other indicators."

Table 5. Top 3 attributes of safety culture

\begin{tabular}{|l|l|}
\hline Top $\mathbf{3}$ attributes of safety culture & Experts Who Responded \\
\hline Adequate Resources & Expert 2, 3, 4, 5, 6 \\
\hline Accountable Executive Support (management commitment & Expert 3, 3, 7 \\
\hline Regulatory Compliance & Expert 4, 5 \\
\hline
\end{tabular}

\subsection{Company Wide SMS Involvement}

When asked if safety should be viewed as equally important to all individuals within an organization, most experts agreed that safety affects all employees and is equally important, as shown in Table 4. The perspective of Expert 1 differed from the others. "[Safety] should not be equally weighted in all departments" (Expert 1). Giving the example of the variation in job functions and exposure to safety, Expert 1 states, "a bomb disposal expert might want to have a greater focus on safety than the person who does his laundry." Expert 3 opposes the perspective of Expert 1, stating that safety should be equally important to all employees in an organization, though some job functions give it less importance.

Expert 2 describes the importance of a companywide involvement: "It is the organization which delivers safety, an organization is a system. The jobs which are performed are a part of the system, which includes safety reporting. Unfortunately, we describe safety reporting as SMS, but SMS is not a thing, it's a concept of safety as our organization, and all jobs affect the organization, because the system delivers safety."

\section{DISCUSSION}

This section includes the consolidation of 164 responses from the survey together with the inputs from expert interviews, in addition to open question responses.

Of all respondents, the largest job function represented were pilots (32\%), followed by administrative staff (19\%), and management (19\%). Maintenance was least represented with only four respondents (2\%). Many respondents listed multiple job functions as their primary 
role. For analysis, we simplified job functions. For example, all participants who selected management and other job functions as primary were categorized as management. More than half $(55 \%)$ of the respondents had ten or more years of industry experience. Many respondents (31\%) had worked for four or more air carriers.

\subsection{Perception of Safety for Canadian Air Carriers Survey}

During the survey, respondents were asked to rate how strongly they agreed or disagreed with the following statements shown in table 6. Using the 5-point Likert rating scale, responses ranging from strongly disagree to disagree and agree to strongly agree were combined. They are reflected as agree and disagree.

Table 6. Survey Questions

\section{Question Description}

The Company's safety perspective/safety policy has a positive effect on my attitude towards safety.

My management provides and example of how to behave, think and act safely.

I find it necessary to modify safety/company procedures to make my job easier

\subsection{Organizational Influences}

Most respondents (69\%) agree that their Company's safety perspective/safety policy positively impacts their attitude towards safety. Of the 164 respondents, one respondent who disagreed with the statement communicated the importance of individual responsibility. This respondent advised, "I have to be more vigilant in my attitude towards safety, to find things that others have overlooked, or to be fully aware of what's going on, possibly to exercise my right to refuse unsafe work." The top three common themes from open question responses are listed in Table 7.

Table 7. Common themes from open question responses

\begin{tabular}{|l|c|}
\hline Themes & Ranking \\
\hline The Company does not deliver/follow up on safety initiatives & 1 \\
\hline Safety is only considered when it is a means to meet regulatory requirements. & 2 \\
\hline Safety is only important to avoid liability issues & 3 \\
\hline
\end{tabular}




\subsection{Management Behaviour}

The majority (65\%) of participants agreed that their management provides an example of how to behave, think, and act safely. These findings are consistent with Wiegmann et al. (2017, p126), who confirm that management has long been recognized as playing a critical role in promoting organizational safety culture. One respondent expressed that as management, they required a "daily push" specific to safety. Expert 5 corroborates the importance of a daily push. Expert 5 states, "certainly when it comes to safety there needs to be a demonstrated commitment by people, that you walk the talk. People are enthusiastic when they are working together with management... there is safety leadership". The top three common themes identified by respondents who did not agree with the statement are listed in Table 8.

Table 8. Common themes from open question responses

\begin{tabular}{|l|c|}
\hline Themes & Ranking \\
\hline Management are punitive with those who disagree with them. & 1 \\
\hline Management violate regulation to generate revenue. & 2 \\
\hline Management provide inadequate solutions/equipment & 3 \\
\hline
\end{tabular}

\subsection{Modifying Procedures}

With buy-in to safety policies, and management as an example for safety behavior, respondents (32\%) agree with the statement "I find it necessary to modify safety/company procedures to make my job easier and more efficient". Dekker and Breakey (2016, p189) assert that when a clear majority of workers routinely avoid certain rules, this signals that the rules are not written with their legitimate interests and their knowledge in mind, or in ignorance of the goal conflicts and resource constraints that drive real work.

One respondent justified procedural shortcoming as follows: "procedures must be adhered to, but it's necessary to keep in mind that I am working with the travelling public and there may be another way to get the same procedure [al] goal accomplished more effectively."

Expert 6 suggests that the most important priority of companies should be "to get the procedures right". The response to this survey question shows that the majority of respondents (54\%) disagree with the need to modify safety/company procedures. Table 9 explores the relationship with two categorical variables using the chi square, and 0.05 level of statistical significance. Industry experience, $\mathrm{X}^{2}(4)=3.58, \mathrm{p}=.47$, and number of air carriers years worked for, $\mathrm{X}^{2}(6)=4.41, \mathrm{p}=.62$, have no statistically significant association with the 
statement "I find it necessary to modify safety/company procedures to make my job easier and more efficient (Q4)". For this question, job function is approaching statistical significance, $\mathrm{x}^{2}(10)=17.64, \mathrm{p}=.06$, in comparison to the other categories.

The top three job functions that modify procedures to simplify their job and improve efficiency include: Maintenance (50\%), Admin/Other (46.9\%), and Flight Attendant respondents (37\%). With only four respondents from the Maintenance job function, it may be more accurate to remove them. With their removal, the top three job functions which modify procedures include Admin/Other, Flight Attendants, and Management (32.3\%) respondents. The Pilots respondents are least likely to modify safety company procedure (17.3\%). One respondent mentioned that procedures "make my job easier."

Table 9. Variables associated with the modification to safety procedures to may make job easier and more efficient.

\begin{tabular}{|l|c|c|c|}
\hline Industry Experience & $\begin{array}{c}\text { Strongly disagree, } \\
\text { disagree }\end{array}$ & Neutral & $\begin{array}{c}\text { Strongly agree, } \\
\text { agree }\end{array}$ \\
\hline 3 years or less & $44.1 \%$ & $23.5 \%$ & $\mathbf{3 2 . 4 \%}$ \\
\hline $4-9$ years & $54.5 \%$ & $12.5 \%$ & $\mathbf{3 5 . 0 \%}$ \\
\hline $\begin{array}{l}\text { Number years airlines } \\
\text { worked for }\end{array}$ & $\begin{array}{c}\text { Strongly disagree, } \\
\text { disagree }\end{array}$ & $12.1 \%$ & $29.7 \%$ \\
\hline 1 & $41.9 \%$ & $16.3 \%$ & $\begin{array}{c}\text { Neutral } \\
\text { agree }\end{array}$ \\
\hline 2 & $58.1 \%$ & $16.1 \%$ & $\mathbf{4 1 . 9 \%}$ \\
\hline 3 & $62.5 \%$ & $12.5 \%$ & $25.8 \%$ \\
\hline 4 or more & $54.9 \%$ & $13.7 \%$ & $\mathbf{3 1 . 4 \%}$ \\
\hline Job Function & $\begin{array}{c}\text { Strongly disagree, } \\
\text { disagree }\end{array}$ & Neutral & $\begin{array}{c}\text { Strongly agree, } \\
\text { agree }\end{array}$ \\
\hline Administration/Other & $37.5 \%$ & $15.6 \%$ & $\mathbf{4 6 . 9 \%}$ \\
\hline Flight Attendant & $48.1 \%$ & $14.8 \%$ & $\mathbf{3 7 . 0 \%}$ \\
\hline Maintenance & $50.0 \%$ & & $\mathbf{5 0 . 0 \%}$ \\
\hline Management & $61.3 \%$ & $6.5 \%$ & $\mathbf{3 2 . 3 \%}$ \\
\hline Operations & $36.8 \%$ & $31.6 \%$ & $\mathbf{3 1 . 6 \%}$ \\
\hline Pilot & $69.2 \%$ & $13.5 \%$ & $17.3 \%$ \\
\hline Not Bold and
\end{tabular}

Note: Bold and italicized values are statistically significant.

The top three common themes that justify deviation from the procedure are: procedures modified to simplify tasks, not complying with obsolete procedures, which are still in circulation, and procedures that are too stringent. 


\subsection{Communication}

Although CAC specifies safety on their websites, the perception of the most communicated message by management within the last 12 months was cost. Expert 2's perspective explains why this inconsistency may exist. Expert 2 discloses that "marketing safety for the engagement of employees and to gain public confidence is easily understood when safety is considered the number one priority, however, we are in business to make money, and one way to make money is through safety, the overall objective is to make money."

Figure 1 shows that most respondents (20\%) rank cost as the number one topic communicated to them in comparison to other messages. The overall message of cost is communicated twice as much in comparison to safety (10.3\%). Although cost is most often communicated to respondents by management, respondents ranked decreasing cost and increasing revenue as their lowest priority of focus $(12.1 \%)$. This question may infer that the messages communicated by management may not have an impact on work focus.

Figure 1: Most communicated management topics within the last 12 months

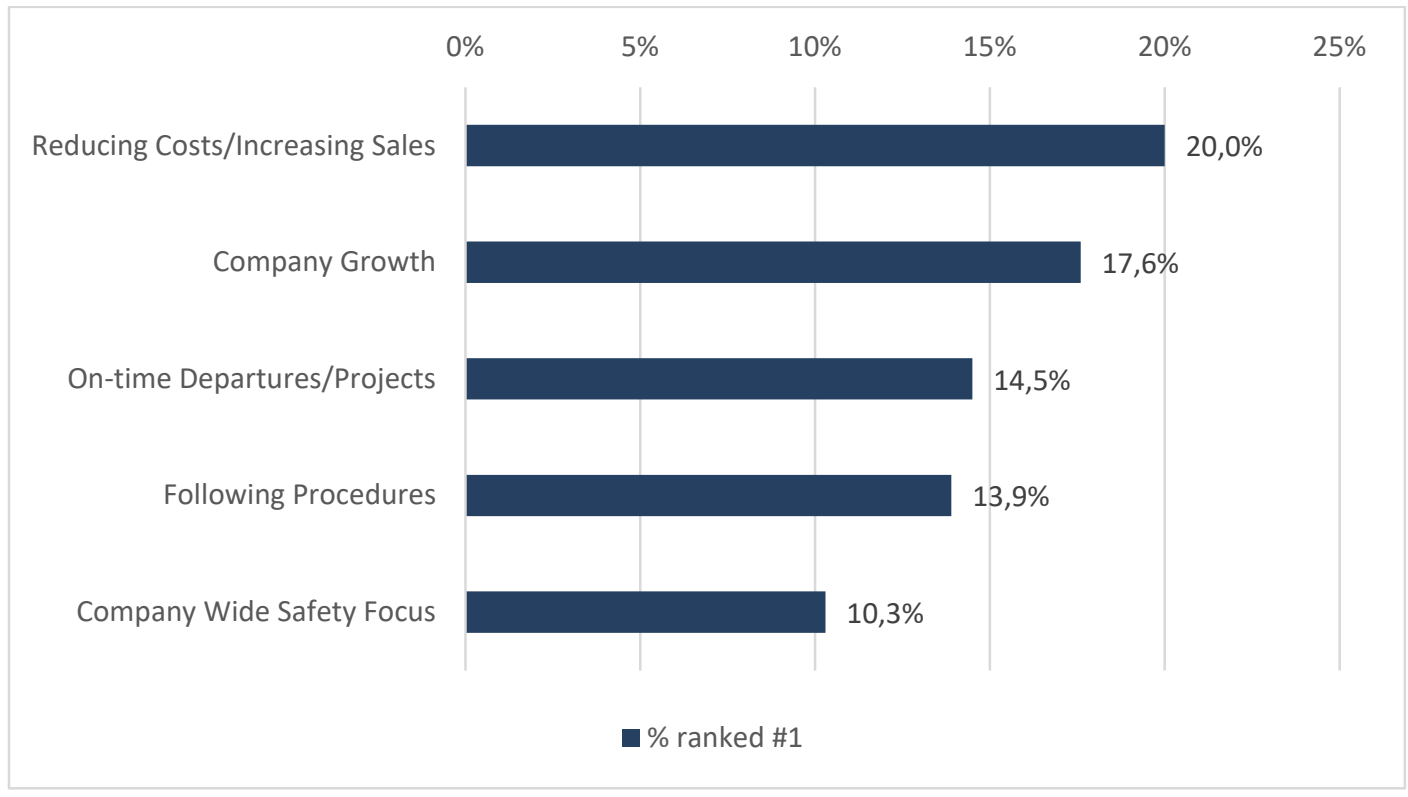

\subsection{Reporting}

The largest area of focus in the survey, which aims to understand the respondents' behavior, is safety reporting. Although reporting is a component of a SMS, reporting behavior from respondents allows the researcher to understand when and why employees contribute to the SMS. 
The top three safety reportable observations that have not been reported include: procedural violations (24.2\%), unsafe behavior (23.0\%), and blocked fire exits, tripping or similar safety hazards (20.6\%). The least unreported is a reportable safety event (an event required by the regulators/company to be reported) (6.7\%). Respondents (50\%) agree that their job exposes them to hazards, which need to be reported, and $55.2 \%$ had not observed any safety related reportable issues at work.

Experts 2, 3, 4, 5, and 6 agree that "conceptually people may believe that they do not see "a reportable occurrence, or that reporting parameters are either too narrow or broad" (Experts 4, 5 and 6). Experts 1, 2, 4, 5 and 6 communicate that they agree that the working environment is a factor, which inhibits reporting (organizational culture). Expert 5 expresses "if the safety culture is such that you don't have confidence that if you report something someone will get fired, it comes down to culture, how management supports things."

\subsection{Organizational and Managerial Impact on Safety Reporting}

Table 10 shows variables considered when exploring the relationships between a company's safety perspective/policy's impact on respondent attitude, management as a safety example, and an impact on reporting events, which include: unsafe acts, unsafe behavior, and unsafe working environment. Statistically significant differences were observed.

When exploring the company's safety perspective/policy across all six categories of reporting events, those who answered "agree" to the statement regarding the positive impact of the safety perspective/policy, are more likely to report safety events compared to the respondents who "disagree." A similar pattern was observed when exploring the relationship between management as a safety example across all six categories of reporting observed events. Those who answered "agree" that management provides a safety example are more also more likely to report events compared to respondents who disagree.

We found that management's behavior and actions have an impact on reporting in five out of six categories. The only event that management does not impact is a known safety event. The lack of statistical significance may be because such events are mandatory reportable as dictated by a regulatory requirement.

In exploring the sub-groups of disagree and agree there is a significant gap difference in reporting safety events. For example,58.8\% of respondents who disagree with the statement "The company's safety perspective/safety policy has a positive effect on my attitude to safety", do not report unsafe working environments in comparison to the $10.5 \%$ who agree with the 
statement and refrain from reporting unsafe working environment. That gap difference indicates that the group that disagrees with the statement is six times less likely to report than those who agree. Similarly, for the same safety event, $52 \%$ of the respondents who disagreed with the statement my management provides an example of how to behave, think and act safely do not report an unsafe working environment in comparison to the $8.3 \%$ who agree with management as an example. Once again, the gap difference indicates that the group that disagrees with the statement is six times less likely to report than those who agree.

Table 10. Exploring factors associated with not reporting safety events

\begin{tabular}{|c|c|c|c|c|c|c|}
\hline \multicolumn{7}{|c|}{ Safety events observed, but not reported } \\
\hline Related question/factor & $\begin{array}{l}\text { Blocked Fire } \\
\text { Exit, Tripping, } \\
\text { or similar } \\
\text { safety hazard }\end{array}$ & $\begin{array}{c}\text { Procedural } \\
\text { Violation }\end{array}$ & Safety Event & Unsafe Act & $\begin{array}{l}\text { Unsafe } \\
\text { Behaviour }\end{array}$ & $\begin{array}{c}\text { Unsafe } \\
\text { Working } \\
\text { Environment }\end{array}$ \\
\hline \multicolumn{7}{|c|}{ The Company's safety perspective/safety policy has a positive effect on my attitude towards safety. } \\
\hline & $\begin{array}{c}\mathrm{X}^{2}(2)=3.07 \\
\mathrm{p}=.22\end{array}$ & $\begin{array}{c}X^{2}(2)=5.94 \\
p=.05\end{array}$ & $\begin{array}{c}X^{2}(2)=3.69 \\
p=.16\end{array}$ & $\begin{array}{c}\mathrm{X}^{2}(2)=11.60 \\
p<.01\end{array}$ & $\begin{array}{c}\mathrm{X}^{2}(2)=16.44 \\
\mathrm{p}<.001\end{array}$ & $\begin{array}{c}X^{2}(2)=24.82 \\
p<.001\end{array}$ \\
\hline $\begin{array}{c}\text { Strongly disagree, } \\
\text { disagree }\end{array}$ & $35.3 \%$ & $47.1 \%$ & $17.6 \%$ & $47.1 \%$ & $58.8 \%$ & 58.5\& \\
\hline Neutral & $23.5 \%$ & $26.5 \%$ & $5.9 \%$ & $20.6 \%$ & $29.4 \%$ & $29.4 \%$ \\
\hline Strongly agree, agree & $17.5 \%$ & $20.2 \%$ & $5.3 \%$ & $13.2 \%$ & $15.8 \%$ & $10.5 \%$ \\
\hline \multicolumn{7}{|c|}{ My management provides an example of how to behave, think and act safely. } \\
\hline & $\begin{array}{c}\mathrm{X}^{2}(2)=6.84 \\
\mathrm{p}=.3\end{array}$ & $\begin{array}{c}X^{2}(2)=9.93 \\
p<.01\end{array}$ & $\begin{array}{c}\mathrm{X}^{2}(2)=0.66 \\
\mathrm{p}=.72\end{array}$ & $\begin{array}{c}\mathrm{X}^{2}(2)=6.19 \\
\mathrm{p}<.05\end{array}$ & $\begin{array}{c}\mathrm{X}^{2}(2)=9.62 \\
p<.01\end{array}$ & $\begin{array}{c}\mathrm{X}^{2}(2)=28.33 \\
\mathrm{p}<.001\end{array}$ \\
\hline $\begin{array}{c}\text { Strongly disagree, } \\
\text { disagree }\end{array}$ & $40.0 \%$ & $36.0 \%$ & $8.0 \%$ & $32.0 \%$ & $40.0 \%$ & $52.0 \%$ \\
\hline Neutral & $18.8 \%$ & $40.6 \%$ & $9.4 \%$ & $25.0 \%$ & $34.4 \%$ & $31.3 \%$ \\
\hline Strongly agree, agree & $16.7 \%$ & $16.7 \%$ & $5.6 \%$ & $13.0 \%$ & $15.7 \%$ & $8.3 \%$ \\
\hline
\end{tabular}

Note: Shown percentages are for not reporting safety event, bold and italicized values are statistically significant.

\subsection{Job Function and Reporting}

Table 11 shows that there is an association between job functions and reporting events. A difference exists in reporting rates based on job functions. Except for procedural violations and reportable incidents, the categories showed a statistically significant relationship. The Admin/Other category (37.5\%) have not reported blocked fire exits, tripping, or similar safety hazards. The Flight Attendant job function responded with the largest percentage of not reporting procedural violations $(40.7 \%)$, reportable incidents of unsafe acts $(40.7 \%)$, unsafe behaviors (44.4\%), and unsafe working environment (44.44\%). 
Table 11. Not reporting events by job category

\begin{tabular}{|l|c|c|c|c|c|c|}
\hline & $\begin{array}{c}\text { Blocked Fire } \\
\text { Exit, Tripping, } \\
\text { or similar } \\
\text { safety hazard }\end{array}$ & $\begin{array}{c}\text { Procedural } \\
\text { Violation }\end{array}$ & Safety Event & Unsafe Act & $\begin{array}{c}\text { Unsafe } \\
\text { Behaviour }\end{array}$ & $\begin{array}{c}\text { Unsafe } \\
\text { Working } \\
\text { Environment }\end{array}$ \\
\hline Job category & $\begin{array}{c}X^{2}(5)=12.88 \\
p=.02\end{array}$ & $\begin{array}{c}X^{2}(5)=5.88 \\
p=.32\end{array}$ & $\begin{array}{c}X^{2}(5)=2.25 \\
p=.81\end{array}$ & $\begin{array}{c}X^{2}(5)=23.23 \\
p<.001\end{array}$ & $\begin{array}{c}X^{2}(5)=10.93 \\
p<.05\end{array}$ & $\begin{array}{c}X^{2}(5)=25.18 \\
p<.001\end{array}$ \\
\hline Administration/Other & $\mathbf{3 7 . 5 \%}$ & $25.0 \%$ & $9.4 \%$ & $\mathbf{3 4 . 4 \%}$ & $\mathbf{2 8 . 1 \%}$ & $\mathbf{3 4 . 5 \%}$ \\
\hline Flight Attendant & $\mathbf{1 8 . 5 \%}$ & $40.7 \%$ & $11.1 \%$ & $\mathbf{4 0 . 7 \%}$ & $\mathbf{4 4 . 4 \%}$ & $\mathbf{4 4 . 5 \%}$ \\
\hline Maintenance & $0 \%$ & $25.0 \%$ & $0 \%$ & $0 \%$ & $\mathbf{2 5 . 0 \%}$ & $\mathbf{2 5 . 0 \%}$ \\
\hline Management & $\mathbf{2 5 . 8 \%}$ & $16.1 \%$ & $6.5 \%$ & $\mathbf{6 . 5 \%}$ & $\mathbf{1 6 . 1 \%}$ & $\mathbf{3 . 2 \%}$ \\
\hline Operations & $\mathbf{2 6 . 3 \%}$ & $26.3 \%$ & $5.2 \%$ & $\mathbf{1 0 . 5 \%}$ & $\mathbf{1 0 . 5 \%}$ & $\mathbf{5 . 3 \%}$ \\
\hline Pilot & $\mathbf{7 . 7 \%}$ & $19.2 \%$ & $3.8 \%$ & $\mathbf{7 . 7 \%}$ & $\mathbf{1 7 . 3 \%}$ & $\mathbf{1 1 . 5 \%}$ \\
\hline
\end{tabular}

Note: Shown percentages are for not reporting safety event, bold and italicized values are statistically significant.

\subsection{Organizational Focus and Priority}

In response to what respondents believe, the most important organizational focus is, most chose profitability (35\%), followed by safety (24\%), and closely followed by customer service (22\%). Respondents believe that employee welfare is of the least focus (3\%).

Table 12. Top Priorities and Focus of the Companies and CAC, $n=164$.

\begin{tabular}{|c|c|}
\hline Focus categories & N (\%) \\
\hline Most important focus for the company as communicated by respondents. \\
\hline Profitability & $58(35 \%)$ \\
\hline Safety & $40(24 \%)$ \\
\hline Customer service & $37(22 \%)$ \\
\hline Expanding the business & $25(15 \%)$ \\
\hline Employee welfare & $5(3 \%)$ \\
\hline What the priority of Canadian air carriers should be. \\
\hline Consider safety implications when making business decisions & $73(44 \%)$ \\
\hline Focus on safety at all costs & $48(29 \%)$ \\
\hline Focus on employee and passenger welfare & $44(27 \%)$ \\
\hline
\end{tabular}

The final question aimed to understand whether both survey respondents and experts believed safety to be the number one priority of CAC. Respondents ( $44 \%$ ) believe that the priority is to consider safety implications when making business decisions. Likewise, all experts agree on the balance between safety and business practices. Expert 5 states:

'If you are not committed to safety, you will not be economically viable. Safety needs to be a consideration. As a number one priority, that is something we aspire to. People may always 
say it, but it's not true. If you're managing your business effectively you will be looking at all aspects (of the organization). Safety leads to good economics'.

\section{CONCLUSION AND RECOMMENDATIONS}

For almost two decades, Justice Moshansky's (1992) declaration has led CAC to believe that there is a decision between safety and profitability; safety being the priority. The declaration of safety as top priority continuously is published throughout TCCA literature and CAC websites.

This research set out to investigate whether safety is the number one priority for CAC and the factors that influence the compliance with TCCASMS program objectives. Through this process, an awareness of what factors safety impacts and what safety has an impact on, were critical to understanding how it is understood by the regulator, industry experts, and employees of CAC.

This research demonstrates that safety as a stated priority by CAC, is in fact not in alignment with the perception of safety's priority. The respondents believe that profitability is the most important focus within their organizations based on the most communicated message. The choice between safety and economic viability must not be an option and should be rebranded to suggest that it is through safety we achieve economic viability. The idea that safety is a choice is false. It is through management's commitment and support in safety management that an organization is held adequately meets safety targets.

CAC management should consider how safety is positioned within an organization and encourage employees to actively participate in a SMS, while creating an effective safety system that incorporates all elements as outlined by the framework of TCCA. Wiegmann et al. (2017) state that if managers are seen to care about safety, employees may feel more engaged. When employees are personally invested in their safety and supported by their management, they are highly motivated to participate in safety initiatives. With the emphasis on organizations, they cannot be expected to operate independently of regulatory enforcement. Regulators must enforce safety requirements for categories of aviation in Canada, not just wide body high-density aircraft.

Safety is not just a set of regulations that are enforced by an inspector and documented through policy, processes and procedures. Measures for industry safety standards and best 
practices have been established by both ICAO and the regulator but require the support and continuous support of management. Based on the finding, we recommend that regulators:

1. Establish a system that holds Accountable Executives responsible for safety. This may be accomplished through the development of third party approved safety audit organizations based on SMS, quality management principles, safety culture criteria, academic and practical standardized criteria that approves safety standards on behalf of the Regulator.

2. Ensure that all individuals responsible for financial decisions, which include the Accountable Executive, other executives and department leadership, attend mandatory safety management training with an approved safety program for leadership.

3. Promote safety and create a responsible and accountable safety culture. The Accountable Executives for all Canadian carriers are required to annually submit an annual plan for organizational safety culture management plan, key performance indicators, followed by a check for effectiveness mechanism such as an audit. This would be reviewed by an approved safety audit organization and certified as acceptable or unacceptable for the regulator.

This template suggests the importance of management's continuous involvement in the safety system (not to be confused with the management aspect of the system), and management's involvement in creating positive safety and organizational culture.

Through safety promotion from SMS data from the reported events or known high risk, information is communicated throughout the organization, placing an emphasis on front line staff and their direct managers (usually middle management). The next step requires that senior leadership commits to safety as an objective to promote profitability through risk management within the organization. Simultaneously, adequate resources, such as training, financial and manpower provided to the safety department. Middle management and employees set safety objectives based on data that has been promoted within the organization. As a result, middle management buys into safety as an objective to promote profitability, and internally, it is promoted within the team. Through this promotion, it feeds into the safety system and adds value to a successful safety culture through the unification of safety views and behavior. The result is economic viability through risk mitigation.

Areas of further research could include aviation's organizational influences on safety, competing priorities impact on safety, the impacts of executive management on aviation 
safety, the regulators' role in mandating organizational safety culture and the Management in the Middle Template.

\section{REFERENCES}

- Antonsen, S., Nilsen, M., \& Almklov, P. G. (2016). Regulating the intangible. Searching for safety culture in the Norwegian petroleum industry. Safety Science, 92, 232-240. https://doi.org/10.1016/j.ssci.2016.10.013

- Bienefeld, N. and Grote, G. (2012) 'Silence That May Kill', Aviation Psychology and Applied Human Factors, 2(1), pp. 1-10. doi: 10.1027/2192-0923/a000021.

- Bosak, J., Coetsee, W. J., \& Cullinane, S. J. (2013). Safety climate dimensions as predictors for risk behavior. Accident Analysis and Prevention, 55, 256-264. https://doi.org/10.1016/j.aap.2013.02.022

- Cambridge Dictionary, http://dictionary.cambridge.org/dictionary/english/priority (Accessed March 7, 2017)

- Canadian Aviation Regulation, SOR-96-433, 1996, http://lawslois.justice.gc.ca/eng/regulations/SOR-96-433/page-1.html\#h-1) (Accessed March 6, 2017)

- Canadian Aviation Regulations (SOR/96-433), Available at: http://www.tc.gc.ca/eng/acts-regulations/regulations-sor96-433.htm (Accessed: March 19, 2017)

- Cohen, T. N., Wiegmann, D. A. and Shappell, S. A. (2015) 'Evaluating the Reliability of the Human Factors Analysis and Classification System.', Aerospace medicine and human performance, 86(8), pp. 728-735. doi: 10.3357/AMHP.4218.2015.

- Efthymiou, M., Arvanitis, P. \& Papatheodorou, A. (2016) Institutional Changes and Dynamics in the European Aviation Sector: Implications for Tourism. In Pappas N. \& Bregoli, I. (eds) Global Dynamics in Travel, Tourism and Hospitality. Hershey Pennsylvania: IGI Global. ISBN: 9781522502012.

- Efthymiou, M., Njoya, E., Lam Lo, P., Papatheodorou, A. and Randall, D. (2019). Ontime performance of British Airways at Heathrow Airport and customer satisfaction. Journal of Aerospace Technology and Management, 11, 1-13. http://dx.doi.org/10.5028/jatm.v11.977. 
- Efthymiou, M. \& Papatheodorou, A. (2018). Evolving Business Models. In Graham, A. and Harper N. (2018) The Routledge Companion to Air Transport Management. Routledge.

- Federal Aviation Association https://www.faa.gov/news/updates/?newsId=93206 2020 Statement from FAA Administrator Steve Dickson on the Special Committee's report on aircraft certification (Accessed: January 18, 2020)

- Federal Aviation Association https://www.faa.gov/news/updates/?newsId=93206 2019 FAA Statement on Lion Air Flight 610 Accident Report (Accessed: January 18, 2020)

- Flight Global https://www.flightglobal.com/analysis/why-boeing-faces-worst-crisis-inits-history/135000.article 2019 Why Boeing faces 'worst crisis' in its history (Accessed: January 18,2020$)$

- Gill, G. K., \& Shergill, G. S. (2004). Perceptions of safety management and safety culture in the aviation industry in New Zealand. Journal of Air Transport Management, 10(4), 231-237.

- Gillen, M., Kools, S., Sum, J., McCall, C., \& Moulden, K. (2004). Construction workers' perceptions of management safety practices: a qualitative investigation. Work, 23(3), 245-256. Retrieved from http://www.ncbi.nlm.nih.gov/pubmed/15579933

- Gnoni, M. G. and Saleh, J. H. (2017) 'Near-miss management systems and observability-in-depth: Handling safety incidents and accident precursors in light of safety principles', Safety Science. Elsevier Ltd, 91, pp. 154-167. doi: 10.1016/j.ssci.2016.08.012.

- Gordon R, Kirwan B, Perrin E. Measuring safety culture in a research and development centre: a comparison of two methods in the Air Traffic Management domain. Safety Science 2007;45(6):669-95

- Håvold, J. I. (2010). Safety culture and safety management aboard tankers. Reliability Engineering and System Safety, 95(5), 511-519.

- Hodgson, Sasha; Al Haddad, Mariam; Al Zaabi Salama; Abdulrahim, S. (2015). MH17: Did safety come first? MIDDLE EAST JOURNAL OF BUSINESS, 10(1), 27-38. Retrieved from

https://extranet.cranfield.ac.uk/,DanaInfo=content.ebscohost.com,SSL+ContentServe r.asp?T $=P \& P=A N \& K=100278691 \& S=R \& D=b t h \& E b s c o C o n t e n t=d G J y M N H r 7 E S e p r I 4 w t$ vhOLCmr06eqLBSrqi4S7SWxWXS\&

- Huang, Y. H., Robertson, M. M., Lee, J., Rineer, J., Murphy, L. A., Garabet, A., \& Dainoff, M. J. (2014). Supervisory interpretation of safety climate versus employee safety climate perception: 
- Huang, Y. hsiang et al. (2017) 'Individual employee's perceptions of ??? Group-level Safety Climate??? (supervisor referenced) versus??? Organization-level Safety Climate??? (top management referenced): Associations with safety outcomes for lone workers', Accident Analysis and Prevention. Elsevier Ltd, 98, pp. 37-45. doi: 10.1016/j.aap.2016.09.016.

- ICAO (2013) ICAO Safety Management Manual (SMM) Doc 9859 AN/474. ICAO. Available at: http://www.icao.int/fsix/_Library/SMM9859_1ed_en.pdf\%5Cnfile://C:/Users/Danilo/Downloads/Safety_management_and_r isk_modelling_in_aviation.pdf\%5Cnhttp://www.easa.eu.int/essi/documents/Methodol ogy.pdf.

- ICAO (2015). A Coordinated, Risk-based Approach to Improving Global Aviation Safety. Montreal. Retrieved from https://www.icao.int/safety/Documents/ICAO_Safety_Report_2015_Web.pdf

- ICAO Annual Safety \& Losses Annual Review, 2015 https://www.flightglobal.com/asset/6729(Flight Global, 2015) (Accessed June 12, 2017)

- ICAO, https://www.icao.int/about-icao/Pages/default.aspx (Accessed May 20, 2017)

- ICAO. ICAO Safety Management Manual (SMM) Doc 9859 AN/474 (2013). ICAO. Retrieved from http://www.icao.int/fsix/_Library/SMM9859_1ed_en.pdf\%5Cnfile://C:/Users/Danilo/Downloads/Safety_management_and_r isk_modelling_in_aviation.pdf\%5Cnhttp://www.easa.eu.int/essi/documents/Methodol ogy.pdf

- ICAO. ICAO Safety Management Manual (SMM) Doc 9859 AN/474 (2013). ICAO. Retrieved from http://www.icao.int/fsix/_Library/SMM9859_1ed_en.pdf\%5Cnfile:///C:/Users/Danilo/Downloads/Safety_management_and_r isk_modelling_in_aviation.pdf\%5Cnhttp://www.easa.eu.int/essi/documents/Methodol ogy.pdf

- International Air Transport Association, Airlines Continue to Improve Profitability 5.1\% Net Profit Margin for 2016h, December 10, 2015 http://www.iata.org/pressroom/pr/Pages/2015-12-10-01.aspx (Accessed June 4, 2017)

- International Air Transport Association, IATA Press Release N0, 8 March 9, 2015 (Accessed June 1, 2017) http://www.iata.org/pressroom/pr/Pages/2015-03-0901.aspx (Accessed June 1, 2017) 
- Janic, M. (2000). An assessment of risk and safety in civil aviation. Journal of Air Transport Management, 6(1), 43-50.

- Kelly, D., \& Efthymiou, M. (2019). An analysis of human factors in fifty controlled flight into terrain aviation accidents from 2007 to 2017. Journal of Safety Research, 69, 155165.

- Lercel Damon, Steckel Rich, Mondello Suzanne, Carr Eddie, P. M. (2011). Aviation Safety Management Systems Return on Investment Study. Saint Louis.

- Lu, H., \& Chen, H. (2015). Does a people-oriented safety culture strengthen miners' rule-following behavior? The role of mine supplies-miners' needs congruence. Safety Science, 76, 121-132.

- Minister of Transport Aeronautics Act (R.S., 1985, C. A-2), http://www.tc.gc.ca/eng/acts-regulations/acts-1985ca-2.htm (Accessed January 11, 2017)

- Murphy, G., \& Efthymiou, M. (2017). Aviation safety regulation in the multi-stakeholder environment of an airport. Journal of Air Transport Studies, 8(2), 1-26.

- O'Connell, J.F., Martinez Avellana, R., Warnock-Smith, D. and Efthymiou, M. (2020). Evaluating Drivers of Profitability for Airlines in Latin America: A Case Study of Copa Airlines. Journal of Air Transport Management, 84, 101727 https://doi.org/10.1016/j.jairtraman.2019.101727.

- O'Connor, P., O'Dea, A., Kennedy, Q., \& Buttrey, S. E. (2011). Measuring safety climate in aviation: A review and recommendations for the future. Safety Science, 49(2), 128138.

- Office of Auditor General of Canada (2012) Report of the Auditor General of Canada to the House of Commons. Ottawa. doi: 10.1121/1.3192333.

- Pinion, C., Brewer, S., Douphrate, D., Whitehead, L., DelliFraine, J., Taylor, W. C., \& Klyza, J. (2017). The impact of job control on employee perception of management commitment to safety. Safety Science, 93, 70-75. https://doi.org/10.1016/j.ssci.2016.11.015

- Reason, James (1997). Managing the risks of organizational accidents. Aldershot: Ashgate. ISBN 1840141042.

- Schein, E. and Scheiner, P. (2016). Organization Culture and Leadership. Somerset: John Wiley \& Sons, Incorporated.

- Siegenthaler, D. (2015) The Nature of Hindrance to System Safety An emic Perspective of the Development of a Safety Management System in the Swiss Air Force., MSc 
THESIS Academic Year: 2014 - 2015. CRANFIELD UNIVERSITY. doi: 10.1017/CBO9781107415324.004.

- Somoo, P. T. (2012). An Exploration of the Relationship Between Safety Management System and Safety Climate in Commercial Aviation. AN. Retrieved from https://www.google.co.uk/url?sa=t\&rct=j\&q=\&esrc=s\&source=web\&cd=1\&cad=rja\& ved=0CC8QFjAA\&url=http://www.maa.mod.uk/linkedfiles/regulation/manualofairsafet y.pdf\&ei=vG6KUtyuG8XChAfMtYDwCA\&usg=AFQjCNHEp_fV2JALzkWohUYqAnBw3e5TQ\&bvm=bv.56643336,d.ZG4

- Transport Canada (2008) 'Advisory Circular', Advisory Circular AC No.: 107-001 Guidance on Safety Management Systems Development, (January). doi: AFS-800 AC 91-97.

- Transport Canada Advisory Circular, (AC) No. 107-001 (2015) https://www.tc.gc.ca/eng/civilaviation/opssvs/managementservices-referencecentreacs-100-107-001-2-456.htm (Accessed June 18, 2017)

- Transport Canada Advisory Circular, (AC) No. 107-001 (2015) https://www.tc.gc.ca/eng/civilaviation/opssvs/managementservices-referencecentreacs-100-107-001-2-456.htm (Accessed June 18, 2017)

- Transport Canada Advisory Circular, (AC) No. 107-001 (2016) https://www.tc.gc.ca/eng/civilaviation/opssvs/managementservices-referencecentreacs-100-107-002-461.htm (Accessed June 18, 2017)

- Transport Canada Advisory Circular, (AC) No. 107-001 (2016) https://www.tc.gc.ca/eng/civilaviation/opssvs/managementservices-referencecentreacs-100-107-002-461.htm (Accessed June 18, 2017)

- Transport Canada https://www.tc.gc.ca/eng/civilaviation/opssvs/managementservices-referencecentreacs-100-107-002-461.htm (Accessed April 11, 2017)

- Transport Canada https://www.tc.gc.ca/eng/civilaviation/opssvs/managementservices-referencecentreacs-100-107-002-461.htm (Accessed April 11, 2017)

- Transport Canada, Advisory Circular (AC) No. 107-002 Safety Management System Development Guide for Smaller Aviation Organizations http://www.tc.gc.ca/eng/civilaviation/opssvs/managementservices-referencecentreacs-100-107-002-461.htm (Accessed February 4, 2017)

- Transport Canada, Advisory Circular (AC) No. 107-002 Safety Management System Development Guide for Smaller Aviation Organizations 
http://www.tc.gc.ca/eng/civilaviation/opssvs/managementservices-referencecentreacs-100-107-002-461.htm (Accessed February 4, 2017)

- Varmazyar, S., Mortazavi, S. B., Arghami, S., \& Hajizadeh, E. (2014). Relationship between organisational safety culture dimensions and crashes. International Journal of Injury Control and Safety Promotion, 23(December), 1-7. https://doi.org/10.1080/17457300.2014.947296

- Von Thaden, T. L., Wiegmann, D. a., \& Shappell, S. A. (2007). Measuring Organizational Factors in Airline Safety.

- Von Thaden, T. L., \& Gibbons, A. M. (2008). The Safety Culture Indicator Scale Measurement System. Retrieved from http://www.aviation.illinois.edu/avimain/s/research/pub_pdfs/techreports/08-03.pdf

- Von Thaden, T., Kessel, J., \& Ruengvisesh, D. (2008). Measuring Indicators of Safety Culture in a

- Wiegmann, D. A., Zhang, H., Von Thaden, T. L., Sharma, G., \& Gibbons, A. M. (2004). Safety culture: An integrative review. The International Journal of Aviation Psychology, 14(2), 117-134.

- Yuan, Z., Li, Y., \& Tetrick, L. E. (2015). Job hindrances, job resources, and safety performance: The mediating role of job engagement. Applied Ergonomics, 51, 163171. https://doi.org/10.1016/j.apergo.2015.04.021

- Zhang, H., Wiegmann, D. A., Thaden, T. L. Von, Sharma, G., \& Mitchell, A. A. (2002). cited in Cox \& Flin, (1998) and OECD Nuclear Agency (1987), 1404-1408.

- Zohar, D., \& Polachek, T. (2014). Discourse-based intervention for modifying supervisory communication as leverage for safety climate and performance improvement: a randomized field study. Journal of Applied Psychology, 99(1), 113124. https://doi.org/10.1037/a0034096

\section{AUTHORS' BIOS}

Angeline Ram is a Ph.D. Student at the University of Waterloo in Geography Environmental Management program. As a graduate from Cranfield University with an MSC in Air Transport Management, Angeline combines an academic approach, with her 18 years of international aviation experience to further the field of applied aviation research. Email: a7ram@uwaterloo.ca 
Dr John F. O'Connell is a Reader in Air Transport Management at the University of Surrey, before this he worked at Cranfield University for 10 years and before that for Boeing and Embry Riddle Aeronautical University. He has published exclusively on aviation related topics that are relevant to industry. Email: frankie.oconnell@surrey.ac.uk

Dr Marina Efthymiou (corresponding author) is an Assistant Professor in Aviation Management at Dublin City University. Prior to this, she was working for University of West London and before that for the International Organisation for the Safety of Air Navigation, EUROCONTROL. Her research interests focus on aviation governance and regulation, sustainability, air traffic management and policy issues. Email: marina.efthymiou@dcu.ie

Dr Eric Tchouamou Njoya is a Senior Lecturer and Course Leader at the University of Huddersfield. He also serves as cluster Co-Director at the Behavioural Research Centre of Huddersfield Business School. His research interests include tourism, air transport and sustainable mobility. He has published in leading academic journals in all these disciplines. Email: E.Njoya@hud.ac.uk 